\title{
Disease Activity and Cytokine Production in Mitogen-Stimulated Peripheral Blood Mononuclear Cells from Patients with Rheumatoid Arthritis
}

\author{
Sukhbir S. Uppal ${ }^{a, d}$ Raj Raghupathy ${ }^{b}$ Sawsan J. Hayat ${ }^{d}$ Joseph C. Longenecker ${ }^{c}$ \\ Mini Abraham ${ }^{a}$ Parvez Rawoot ${ }^{b}$ \\ Departments of a Medicine, ${ }^{b}$ Microbiology and ${ }^{c}$ Community Medicine, Faculty of Medicine, Kuwait University, and \\ ${ }^{\mathrm{d}}$ Department of Medicine, Mubarak Al Kabeer Hospital, Kuwait
}

\section{Key Words}

Arthritis - Rheumatoid arthritis · Cytokines • Interferon- $\gamma$ •

Peripheral blood mononuclear cells

\begin{abstract}
Objective: To test whether there are differences in the levels and ratios of 6 pro- and 3 anti-inflammatory cytokines produced by mitogen-stimulated peripheral blood mononuclear cells (PBMCs) in rheumatoid arthritis (RA) subjects compared to controls. Subjects and Methods: 79 participants (42 seropositive RA patients and 37 healthy controls) were enrolled in this study. The production levels in mitogen-stimulated PBMCs of the 6 proinflammatory cytokines (IFN- $\gamma$, TNF- $\alpha$, TNF- $\beta$, IL-8, IL-17, IL-18) and 3 anti-inflammatory cytokines (IL-4, IL-10, IL-13) were assayed by ELISA using kits obtained from Immunotech SA. The ratios of pro- to anti-inflammatory cytokines were calculated for all participants. Results: There were significantly elevated levels of IL-8 and IL-10, and reduced levels of IFN- $\gamma$, IL-4, and IL-17 in mitogenstimulated PBMC culture supernatants of RA subjects compared to controls. Of the 18 pro-/anti-inflammatory cytokine ratios, 3 ratios (TNF- $\alpha /$ IL13, IL-8/IL-4 and IL-8/IL-13) were significantly higher in RA patients compared to controls; and 6 were higher in controls (IFN- $\gamma /$ IL-4; IFN- $\gamma /$ IL-10; IFN- $\gamma /$ IL-13;
\end{abstract}

TNF- $\beta /$ IL10; IL-17/IL-10; IL-18/IL-10). Conclusions: Activated PBMCs of RA patients, regardless of disease activity, showed higher-level production of IL-8 and IL-10 compared to controls; lower-level production of IFN- $\gamma$, IL-4, and IL-17; and elevated ratios of TNF- $\alpha /$ IL-13, IL-8/IL- 4 and IL-8/IL-13.

Copyright $\odot 2009$ S. Karger AG, Basel

\section{Introduction}

Cytokines are intimately involved in the pathogenesis of rheumatoid arthritis (RA) and are key mediators of inflammation. These extracellular signaling molecules can be found in abundance both in the joint and blood of patients with RA. Cytokine functions in RA are complex, with different cytokines possessing biologically overlapping pro- and anti-inflammatory functions, and having the ability to regulate the production of other cytokines. An imbalance between pro- and anti-inflammatory cytokines at the synovial level is a key concept in the predisposition to initiation or perpetuation of rheumatoid synovitis [1].

However, though there is abundant and clear literature about cytokine production in the rheumatoid synovium, information about cytokine production from pe-

\section{KARGER}

Fax +4161306 1234

E-Mail karger@karger.ch

www.karger.com
(C) 2009 S. Karger AG, Basel

1011-7571/10/0191-0033\$26.00/0

Accessible online at:

www.karger.com/mpp
Dr. Sukhbir S. Uppal

Department of Medicine, Faculty of Medicine

Kuwait University, PO Box 24923

Safat 13110 (Kuwait)

Tel. +965 531200 ext. 6319, Fax +965 533 8907, E-Mail uppalss@hsc.edu.kw 
ripheral blood mononuclear cells (PBMCs) is limited and inconsistent. Hence, we tested the hypothesis that there might be differences in the levels of cytokines produced by mitogen-stimulated PBMCs in RA subjects compared to controls, and that these cytokine levels may also differ according to disease activity.

We measured the mitogen-stimulated production levels of selected pro- and anti-inflammatory cytokines in isolated PBMCs of RA patients with active disease and patients in remission compared to healthy controls, and calculated their ratios in order to identify differences in cytokine levels and ratios depending on RA activity.

\section{Subjects and Methods}

\section{Study Population}

Twenty-two consecutive seropositive RA patients in remission and 20 consecutive seropositive patients with active RA were recruited. All 42 patients (27 females, 15 males) fulfilled the American College of Rheumatology criteria for RA [2] and gave informed consent for participating in the study.

Complete clinical and laboratory evaluations were conducted for the patients. Data were entered into a predesigned form. Standardized joint counts, including tender joints and swollen joints, were recorded. The 3-variable DAS28 (DAS28-3) (http://www. das-score.nl/www.das-score.nl/) was computed using the formula [3]: $1.08[0.56 \times \sqrt{ }(\mathrm{TJC})+0.28 \times \sqrt{ }(\mathrm{SJC})+0.70 \cdot \ln (\mathrm{ESR})]$, where $\mathrm{TJC}=$ tender joint count, $\mathrm{SJC}=$ swollen joint count and $\mathrm{ESR}=$ erythrocyte sedimentation rate

A cut-off point of $<2.6$ was used for the DAS28-3 to define remission, corresponding to fulfillment of the modified American Rheumatology Association criteria for remission [4]. According to these preliminary criteria for clinical remission in RA, a state of clinical remission is reached when 5 of the following 6 criteria are fulfilled for at least 2 consecutive months: morning stiffness $\leq 15$ min; no fatigue; no joint pain (by history); no joint tenderness or pain on motion; no soft tissue swelling in joints or tendon sheaths; ESR $<30 \mathrm{~mm} / \mathrm{h}$ for females or $<20 \mathrm{~mm} / \mathrm{h}$ for males [5].

Treatment strategy for RA patients followed recently published guidelines [6]. All patients were treated with disease-modifying antirheumatic drugs (DMARDs) and/or biologicals and, whenever appropriate, nonsteroidal anti-inflammatory drugs and/or corticosteroids were added. The DMARDs used included methotrexate, sulfasalazine, hydroxychloroquine, leflunomide and injectable gold. The biologics used were infliximab, etanercept, adalimumab and rituximab.

Thirty-seven age- and sex-matched healthy controls were also enrolled in the study.

\section{Mitogen-Induced Stimulation of PBMCs}

A sample of $5 \mathrm{ml}$ of peripheral blood was collected from each patient and control. The PBMCs were separated by Ficoll-Hypaque (Pharmacia Biotech, Uppsala, Sweden) density gradient centrifugation, suspended in RPMI medium (Gibco BRL, Gaithersburg, Md., USA) containing $10 \%$ fetal calf serum, aliquoted into 96 -well tissue culture plates at a density of $10^{5}$ cells per well and then stimulated with the mitogen phytohemagglutinin (Sigma Chemicals, St. Louis, Mo., USA) at a concentration of $5 \mu \mathrm{g} / \mathrm{ml}$ for $96 \mathrm{~h}$. Supernatants were collected $96 \mathrm{~h}$ later for estimation of cytokines. This duration of incubation was chosen because previous experiments in our laboratory have shown optimal production of these cytokines after $96 \mathrm{~h}$ incubation (data not shown).

\section{Estimation of Cytokine Levels in Culture Supernatants}

Levels of the proinflammatory cytokines IFN- $\gamma$, TNF- $\alpha$, TNF- $\beta$, IL-8, and IL-18, and anti-inflammatory cytokines IL- 4, IL-10 and IL-13 produced by PBMCs in culture were assayed by ELISA using kits obtained from Immunotech SA (Marseilles, France). The manufacturer's protocols were followed for these assays, which are based on the antibody sandwich principle. The samples and standards were first incubated with a solid-phase monoclonal antibody which captured the specific cytokine present. The solid-phase-bound cytokine was then incubated with a second antibody such as biotinylated anticytokine antibody. The resulting antigen-antibody complexes were then incubated with a streptavidin-enzyme conjugate after which the substrate and chromogen were added. Resultant color development, which was directly proportional to the concentration of the cytokine present in the sample or standard, was stopped and the absorbance value read using an ELISA reader. Samples were analyzed in triplicates. Accurate sample concentrations of cytokines were determined by comparing their respective absorbances with those obtained for the reference standards plotted on a standard curve. The sensitivities of the assays were as follows: $3 \mathrm{pg} / \mathrm{ml}$ of IFN- $\gamma, 10 \mathrm{pg} / \mathrm{ml}$ of TNF- $\alpha, 5 \mathrm{pg} / \mathrm{ml}$ of TNF- $\beta, 3 \mathrm{pg} / \mathrm{ml}$ of IL- $8,15 \mathrm{pg} / \mathrm{ml}$ of IL-17, $10 \mathrm{pg} / \mathrm{ml}$ of IL-18, $5 \mathrm{pg} / \mathrm{ml}$ of IL-4, $5 \mathrm{pg} / \mathrm{ml}$ of IL-10 and $5 \mathrm{pg} / \mathrm{ml}$ of IL-13.

\section{Data Analysis}

Data were analyzed using Stata version 8.0. Means, standard deviations, medians, interquartile range, and proportions were used as descriptive statistics where appropriate. Student's t test was used to test significance for the comparison of means of normally distributed variables between two groups. The significance of associations between categorical variables was tested using the $\chi^{2}$ test and Fisher's exact test, where appropriate. All the cytokine variables were severely skewed, and log transformation did not result in normally distributed transformed variables. Therefore, the nonparametric Mann-Whitney U test was used to test the significance of differences in median cytokine levels between two groups. Correction for multiple comparisons was made using the Bonferroni method. The $\alpha$-level of significance was divided by 9 for the comparison of cytokine levels to account for the analysis of 9 cytokines, and divided by 18 for the comparison of cytokine ratios to account for the analysis of 18 cytokine ratios. However, further decrements in $\alpha$ based on the 'all patients versus controls' and 'patients with active disease versus controls' comparisons were deemed too stringent because the patients with active disease represent a subset of all patients, resulting in a high degree of correlation between the 'active' and 'total patient' groups. Spearman correlation was used to test the significance and magnitude of the correlations between cytokine levels. In an additional analysis of these 15 correlations, the $\alpha$-level was multiplied by 15 to correct for multiple comparisons. 
Table 1. Characteristics of study participants

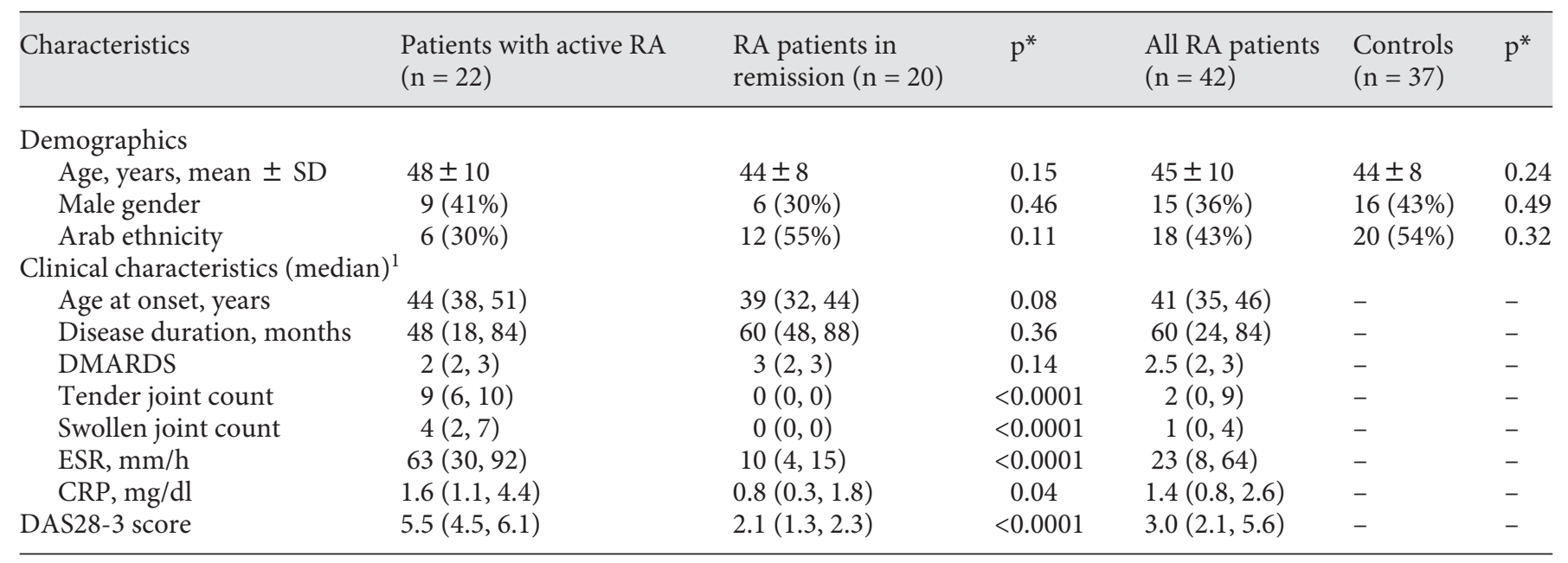

ESR according to Westergren; CRP = C-reactive protein; DAS28-3 = Disease Activity Score-28, measured using 3 variables (tender joint count, swollen joint count, and ESR).

* $\mathrm{p}$ values generated by the $\mathrm{t}$ test, $\chi^{2}$ test, or Mann-Whitney $\mathrm{U}$ test, where appropriate.

${ }^{1}$ Figures in parentheses are 25 th and 75 th percentile.

\section{Results}

The patient characteristics are shown in table 1 . The active and remission groups were similar with regard to age at disease onset, mean disease duration, and mean number of DMARDs for current treatment. Patients in the active group had significantly higher values for tender joint count, swollen joint count, ESR, C-reactive protein and DAS28-3 scores. The disease and control groups were similar with respect to age and gender.

\section{Cytokine Levels and Ratios in Patients with Active}

Disease and Patients in Remission Compared to

\section{Healthy Controls}

Production levels by mitogen-stimulated PBMCs of 6 proinflammatory cytokines (IFN- $\gamma$, TNF- $\alpha$, TNF- $\beta$, IL-8, IL-17, IL-18) and 3 anti-inflammatory cytokines (IL-4, IL-10, IL-13) are presented in table 2, according to study subgroup. No statistically significant differences were found in any cytokine levels between the patients with active disease and those in remission. However, the inflammatory cytokine IL- 8 was produced at significantly higher levels in the active $(\mathrm{p}=0.02)$ and total $(\mathrm{p}=0.003)$ groups of RA patients as compared to healthy controls. Paradoxically, IL-17 and IFN- $\gamma$ were both significantly lower in both the total patient group and the group with active RA, compared to controls. Levels of the anti-in- flammatory cytokine IL- 4 were lower in the group with active RA ( $p=0.01)$ and the total RA group ( $p=0.01)$ when compared to the control group, although the IL-10 levels were significantly higher in the total patient group and the group with active RA compared with controls. After Bonferroni adjustment, only the associations for IL-8 and IL-10 remained statistically significant (comparing the total patient group to controls).

The ratios of proinflammatory to anti-inflammatory cytokines that were significantly associated with the study subgroups are presented in table 3 . No ratios were statistically significantly different between the group with active RA and the group in remission. The only 3 ratios of pro- to anti-inflammatory cytokines that were significantly higher in the total patient group and the group with active RA compared to controls were TNF- $\alpha /$ IL-13, IL-8/IL-4 and IL-8/IL-13. On the contrary, TNF- $\beta /$ IL-10, IL-17/IL-10, IL-18/IL-10 and the 3 IFN- $\gamma$ ratios were significantly lower in the total patient group compared to the controls, and all but 1 (IFN- $\gamma / \mathrm{IL}-4)$ of these were significantly lower in the group with active RA compared with the controls. The ratios retaining statistical significance after Bonferroni correction included IL-8/IL-13, IFN- $\gamma /$ IL-10, TNF- $\beta /$ IL-10, IL-17/IL-10, and IL-18/IL-10.

Table 4 presents the correlations among the proinflammatory cytokines. The correlations among IFN- $\gamma$, 
Table 2. Median mitogen-stimulated cytokine levels according to study subgroup

\begin{tabular}{|c|c|c|c|c|c|c|c|c|c|c|c|}
\hline $\begin{array}{l}\text { Cytokines, } \\
\mathrm{pg} / \mathrm{ml}\end{array}$ & median & IQR & median & IQR & $\begin{array}{l}\mathrm{p} \\
(\mathrm{A} \text { vs. } \mathrm{R})\end{array}$ & median & IQR & median & IQR & $\begin{array}{l}\mathrm{p} \\
(\mathrm{P} \text { vs. } \mathrm{C})\end{array}$ & $\begin{array}{l}\mathrm{p} \\
(\mathrm{A} \text { vs. } \mathrm{C})\end{array}$ \\
\hline \multicolumn{12}{|c|}{ Proinflammatory } \\
\hline IFN- $\gamma$ & 11,749 & 58,563 & 13,160 & 46,790 & 0.69 & 12,047 & 51,096 & 42,784 & 77,525 & 0.009 & 0.02 \\
\hline $\mathrm{TNF}-\alpha$ & 5,311 & 1,2147 & 4,508 & 6,137 & 0.72 & 4,967 & 10,646 & 5,296 & 8,466 & 0.85 & 0.63 \\
\hline IL-17 & 15 & 152 & 15 & 102 & 0.99 & 15 & 114 & 90 & 260 & 0.016 & 0.046 \\
\hline IL-18 & 69 & 83 & 81 & 138 & 0.72 & 69 & 110 & 140 & 132 & 0.10 & 0.08 \\
\hline \multicolumn{12}{|c|}{ Anti-inflammatory } \\
\hline IL-4 & 5.0 & 0.0 & 5.0 & 12 & 0.10 & $5.0^{1}$ & 0.0 & $5.0^{1}$ & 43 & 0.03 & 0.01 \\
\hline IL-10 & 2,707 & 2,225 & 2,270 & 2,745 & 0.99 & 2,447 & 2,304 & 1,223 & 797 & $0.003^{2}$ & 0.02 \\
\hline
\end{tabular}

${ }^{1}$ Mean IL-4 in patients, $12.1 \mathrm{pg} / \mathrm{ml}$; in controls, $86.5 \mathrm{pg} / \mathrm{ml}$ (large difference in means owing to extreme outliers).

${ }^{2}$ Remains statistically significant after Bonferroni correction for multiple comparisons. All p values generated using the MannWhitney U test.

Table 3. Pro-/anti-inflammatory mitogen-stimulated cytokine ratios according to study subgroup

\begin{tabular}{|c|c|c|c|c|c|c|c|c|c|c|c|}
\hline $\begin{array}{l}\text { Pro-/anti-inflam- } \\
\text { matory ratios }^{1}\end{array}$ & median & IQR & median & IQR & $\begin{array}{l}\mathrm{p} \\
\text { (A vs. R) }\end{array}$ & median & IQR & median & IQR & $\begin{array}{l}\mathrm{p} \\
(\mathrm{P} \text { vs. } \mathrm{C})\end{array}$ & $\begin{array}{l}\mathrm{p} \\
(\mathrm{A} \text { vs. } \mathrm{C})\end{array}$ \\
\hline IFN- $\gamma / \mathrm{IL}-4$ & 2,273 & 2,925 & 1,556 & 2,692 & 0.71 & 1,847 & 2,947 & 3,592 & 11,003 & 0.04 & 0.18 \\
\hline IFN- $\gamma / \mathrm{IL}-10$ & 5.3 & 12.4 & 8.3 & 34.2 & 0.48 & 6.4 & 21.8 & 27.4 & 50.3 & $0.0016^{2}$ & $0.0019^{2}$ \\
\hline IFN- $\gamma / \mathrm{IL}-13$ & 113 & 264 & 247 & 579 & 0.33 & 180 & 518 & 250 & 523 & 0.055 & 0.02 \\
\hline IL-8/IL-4 & 30,400 & 29,300 & 23,400 & 28,050 & 0.25 & 25,300 & 27,672 & 10,759 & 21,022 & 0.008 & 0.0074 \\
\hline IL-8/IL-13 & 1,557 & 1,238 & 1,820 & 2,831 & 0.67 & 1,697 & 2,110 & 784 & 958 & $0.0007^{2}$ & 0.0058 \\
\hline IL-17/IL-10 & 0.02 & 0.06 & 0.01 & 0.11 & 0.99 & 0.01 & 0.08 & 0.10 & 0.19 & $0.0007^{2}$ & $0.0028^{2}$ \\
\hline IL-18/IL-10 & 0.03 & 0.05 & 0.03 & 0.15 & 0.65 & 0.03 & 0.07 & 0.09 & 0.13 & $0.0005^{2}$ & $0.0008^{2}$ \\
\hline
\end{tabular}

\footnotetext{
${ }^{1}$ Only statistically significant associations are presented in this table; associations for all other ratios were statistically not significant.

${ }^{2}$ Remains statistically significant after Bonferroni correction for multiple comparisons. All p values generated using the MannWhitney U test.
}

TNF- $\alpha$, and TNF- $\beta$ were very high (all above 0.67 ) and highly statistically significant, even after Bonferroni correction for multiple comparisons. IL-18 was weakly correlated with IFN- $\gamma\left(\mathrm{r}_{\mathrm{s}}=0.22, \mathrm{p}=0.047\right)$, but this correlation did not remain statistically significant after Bonferroni correction. The correlations among the anti-in- flammatory cytokines were as follows: between IL-4 and IL-10, $\mathrm{r}_{\mathrm{s}}=-0.22(\mathrm{p}<0.0005$, and remains statistically significant after Bonferroni correction); between IL-4 and IL-13, $\mathrm{r}_{\mathrm{s}}=-0.22(\mathrm{p}=0.87)$, and between IL-13 and IL-10, $\mathrm{r}_{\mathrm{s}}=0.18(\mathrm{p}=0.11)$. 
Table 4. Spearman correlations between mitogen-stimulated proinflammatory cytokine levels

\begin{tabular}{llrrrcc}
\hline & & IL-8 & IL-17 & IL-18 & IFN- $\gamma$ & TNF- $\alpha$ \\
\hline TNF- $\beta$ & $\mathrm{r}_{\mathrm{s}}$ & 0.06 & 0.07 & 0.01 & 0.67 & 0.68 \\
& $\mathrm{p}$ & 0.61 & 0.55 & 0.95 & $<0.0005^{1}$ & $<0.0005^{1}$ \\
TNF- $\alpha$ & $\mathrm{r}_{\mathrm{s}}$ & 0.12 & -0.11 & 0.15 & 0.86 & \\
& $\mathrm{p}$ & 0.28 & 0.32 & 0.19 & $<0.0005^{1}$ & \\
IFN- $\gamma$ & $\mathrm{r}_{\mathrm{s}}$ & 0.07 & 0.08 & 0.22 & & \\
& $\mathrm{p}$ & 0.52 & 0.49 & 0.047 & & \\
IL-18 & $\mathrm{r}_{\mathrm{s}}$ & -0.12 & 0.19 & & & \\
& $\mathrm{p}$ & 0.31 & 0.09 & & & \\
IL-17 & $\mathrm{r}_{\mathrm{s}}$ & 0.06 & & & & \\
& $\mathrm{p}$ & 0.57 & & & & \\
\hline
\end{tabular}

\footnotetext{
${ }^{1}$ Remains statistically significant after Bonferroni correction for multiple comparisons.
}

\section{Discussion}

The physiology of cytokine pathways in RA is complex, in part due to the large number of molecules involved, and in part due to the redundant and synergistic nature of this network [7]. Disease results when an imbalance in the cytokine network develops. The picture is less clear in the peripheral blood of RA patients, with one study demonstrating a Th1 phenotype [8], while another, published the same year, showed a Th2 over Th1 bias [9].

IFN- $\gamma$ is considered the signature Th1 cytokine which plays a crucial role in the development of RA synovitis through upregulation of IL-12, and an elevated IFN- $\gamma /$ IL- 4 ratio in synovial tissue in RA patients has been demonstrated [10]. In the peripheral blood, however, the situation is different. Activated PBMCs of RA patients produce lower levels of IFN- $\gamma$ when compared to healthy controls [11], and a similar underproduction has been seen in patients with active RA when compared to patients in remission [12]. While our study did not find a significant difference between the group with active RA and the group in remission, stimulated IFN- $\gamma$ levels were significantly lower in the total patient group compared with the controls, confirming the previous findings.

Conflicting results were published on the levels of TNF- $\alpha$ produced by PBMCs from RA patients. Thus, it has been variously reported that the PBMCs of patients with RA produce reduced levels [13], the same levels [14], and higher levels [15] of TNF- $\alpha$ when compared to PBMCs from healthy controls. As regards disease activity and TNF- $\alpha$ levels, it has been recently reported that RA patients with high disease activity have significantly high blood concentrations of TNF- $\alpha$ as compared to patients with moderate and mild disease activity [16]. In this study, we found the levels of TNF- $\alpha$ in the groups with active RA, the group in remission and the total RA group to be no different from those in the healthy control group.

The levels of TNF- $\beta$ are reported to be low or negligible in the sera and synovial fluids of RA patients [17], and no different from healthy controls [18]. Also, they do not correlate with RA disease variables and are not a good marker of RA activity [19]. There is no literature available regarding peripheral blood levels of TNF- $\beta$. We found no differences in the levels of TNF- $\beta$ secreted by mitogenstimulated blood cells in the group with active RA, the group in remission, the total RA group and healthy controls.

Though remarkable elevations of IL-8 (a potent chemoattractant for neutrophils) levels in the bone marrow of patients with RA have been demonstrated and show a close relationship to the extent of synovial proliferation [20], until recently there was no information about the peripheral blood production levels of this cy tokine. In the present study, we have demonstrated significantly elevated levels of IL-8 production in the group with active RA, the group in remission and the total RA group compared to healthy controls, as in a previous report [21]. These findings may indicate the possibility of using IL-8 levels as a marker of RA.

The cytokine IL-17 is an important newly discovered regulator of immune responses. Evidence suggesting that RA is primarily a Th17-mediated disease is rapidly accumulating [22]. Overproduction of IL-17 at the synovial level is well established [23-25]. This may thus account for the observed undersecretion of this cytokine by blood cells as shown in this study, emphasizing the notion that some cytokines that are active in the synovial milieu may be deficient in the peripheral blood.

Some studies have demonstrated elevated serum levels of IL-18 (a new member of the IL-1 family of proinflammatory cytokines) in RA patients compared with controls $[26,27]$. However, a previous report found that both RA and control PBMCs produce similar, very low IL-18 mRNA expression levels [14], as in our study, where the levels of IL-18 produced by PBMCs from patients with active RA, the group in remission and patients from the total RA group were not different from those in the healthy controls. 
It was previously shown that the production of IL-4, an anti-inflammatory cytokine, is higher [28] and the IFN- $\gamma /$ IL-4 ratio, which reflects the Th1/Th2 cytokine balance in blood, is lower in the peripheral blood of RA patients than in healthy controls [9]. However, two subsequent studies found the spontaneous IL-4 mRNA to be significantly lower in RA patients compared to healthy controls $[11,29]$. In agreement with these reports, our study showed lower levels of IL-4 in the total RA group than in controls. We have also found higher IL-8/IL-4 ratios in the active and total RA groups compared to controls, which is consistent with the finding that PBMCs from RA patients produce lower levels of this Th2 cytokine in the peripheral blood compared to healthy controls.

Increased circulating and synovial levels of IL-10 (another anti-inflammatory cytokine) have been previously documented [30]. In our study, the levels of IL-10 were significantly higher as well in the group with active RA and the total RA group compared to the healthy controls, and the ratios of IFN- $\gamma / \mathrm{IL}-10$ and TNF- $\beta / \mathrm{IL}-10$ were correspondingly significantly lower in the group with active RA compared to healthy controls.

IL-13, a Th2 anti-inflammatory cytokine which inhibits IL-17 [31], is increased in RA sera versus normal sera [32]. We found that even though the levels of IL-13 in the group with active RA and the total RA group are not different from those in the healthy controls, the TNF- $\alpha$ / IL-13 ratio is significantly higher in the total RA group compared to healthy controls, suggesting an anti-inflammatory bias in RA PBMCs with regard to IL-13, since TNF- $\alpha$ is the same in the two groups.

Thus, overall we found significantly higher levels of IL-8 and IL-10 production by mitogen-stimulated blood cells and lower levels of IFN- $\gamma$, IL- 4 and IL-17 in RA patients compared to controls. Activated PBMCs of RA patients regardless of disease activity, showed a high-level production of IL-8 and a low-level production of IL- 4 .
While interpreting these data, we ought to keep in mind the possibility that the treatment regimens may by themselves influence cytokine levels. However, in our study it was noted that regardless of which medications were used to induce remission in RA patients, there were no significant differences in the cytokine levels or ratios in patients with active disease compared to those in remission. The effects of DMARD on cytokine levels in RA are not consistent, with most studies showing mixed results [33-35]. It has been hypothesized that DMARD may lead to restoration of peripheral cell-mediated immunity as a response to treatment [34].

A most interesting observation was the lack of any significant differences in peripheral blood mitogen-stimulated cytokine levels or ratios between the group with active RA and the RA group in remission. This may imply that pro- and anti-inflammatory cytokine profiles seen at the synovial level may not translate into similar phenomena at the peripheral blood level. This stands to reason as the cytokines are produced at more intense levels at the synovial level than at the peripheral blood level, the former being the chief site of production and action of these cytokines [7]. Such differences in results between mitogen-stimulated PBMC cytokine production, serum levels and local levels in the synovium or synovial fluid can be attributed to the source and location of various cytokines.

\section{Conclusion}

Activated PBMCs of RA patients, regardless of disease activity, showed higher-level production of IL- 8 and IL-10 compared to controls, lower-level production of IFN- $\gamma$, IL- 4 , and IL-17, and elevated ratios of TNF- $\alpha$ / IL-13, IL-8/IL-4 and IL-8/IL-13.

\section{References}

1 Arend WP: Cytokine imbalance in the pathogenesis of rheumatoid arthritis: the role of interleukin-1 receptor antagonist. Semin Arthritis Rheum 2001;30:1-6.

2 Arnett FC, Edworthy SM, Bloch DA, McShane DJ, Fries JF, Cooper NS, Healey LA, Kaplan SR, Liang MH, Luthra HS, et al: The American Rheumatism Association 1987 revised criteria for the classification of rheu- matoid arthritis. Arthritis Rheum 1988;31: 315-324.

-3 Prevoo ML, van 't Hof MA, Kuper HH, van Leeuwen MA, van de Putte LB, van Riel PL: Modified disease activity scores that include twenty-eight-joint counts. Development and validation in a prospective longitudinal study of patients with rheumatoid arthritis. Arthritis Rheum 1995;38:44-48.

\footnotetext{
4 Fransen J, Creemers MC, van Riel PL: Remission in rheumatoid arthritis: agreement of the disease activity score (DAS28) with the ARA preliminary remission criteria. Rheumatology (Oxford) 2004;43:1252-1255.

-5 Pinals RS, Masi AT, Larsen RA: Preliminary criteria for clinical remission in rheumatoid arthritis. Arthritis Rheum 1981;24:13081315.
} 
-6 American College of Rheumatology Subcommittee on Rheumatoid Arthritis Guidelines: Guidelines for the management of rheumatoid arthritis: 2002 update. Arthritis Rheum 2002;46:328-346.

7 Arend WP: Physiology of cytokine pathways in rheumatoid arthritis. Arthritis Rheum 2001;45:101-106

> Kusaba M, Honda J, Fukuda T, Oizumi K: Analysis of type 1 and type $2 \mathrm{~T}$ cells in synovial fluid and peripheral blood of patients with rheumatoid arthritis. J Rheumatol 1998;25:1466-1471.

\9 Haddad A, Bienvenu J, Miossec P: Increased production of a Th2 cytokine profile by activated whole blood cells from rheumatoid arthritis patients. J Clin Immunol 1998; 18: 399-403.

10 Canete JD, Martinez SE, Farres J Sanmarti R, Blay M, Gomez A, Salvador G, Munoz-Gomez J: Differential Th1/Th2 cytokine patterns in chronic arthritis: interferon gamma is highly expressed in synovium of rheumatoid arthritis compared with seronegative spondyloarthropathies. Ann Rheum Dis 2000;59:263-268.

- 11 Loubet-Lescoulie P, Constantin A, Mazieres B, Tkaczuk J, de Préval C, Cantagrel A: Decreased peripheral blood $\mathrm{T}$ cell cytokine gene expression in rheumatoid arthritis. Scand J Rheumatol 1999;28:244-251.

$>12$ Reuter A, Bernier J, Vrindts-Gevaert Y, Meuleman-Gathy R, Malaise M, Fiers W, Franchimont P: Production of interferon gamma by peripheral blood mononuclear cells from normal subjects and from patients with rheumatoid arthritis. Clin Exp Rheumatol 1988;6:347-354.

-13 Forrest CM, Harman G, McMillan RB, Stoy N, Stone TW, Darlington LG: Modulation of cytokine release by purine receptors in patients with rheumatoid arthritis. Clin Exp Rheumatol 2005;23:89-92.

-14 Rodenburg RJ, van den Hoogen FH, van de Putte LB, van Venrooij WJ: Peripheral blood monocytes of rheumatoid arthritis patients do not express elevated TNF alpha, IL-1 $\beta$, and IL-8 mRNA levels. A comparison of monocyte isolation procedures. J Immunol Methods 1998;221:169-175.

15 Raghav SK, Gupta B, Agrawal C, Chaturvedi VP, Das HR: Expression of TNF-alpha and related signaling molecules in the peripheral blood mononuclear cells of rheumatoid arthritis patients. Mediators Inflamm 2006; 2006:12682.
16 Petrovic-Rackov L: Evaluation of the degree of clinical rheumatoid arthritis activity based on the concentrations of cytokines TNF-alpha, IL-12, IL-15, and IL-18 in serum and synovial fluid (in Serbian). Vojnosanit Pregl 2006;63:21-26.

17 Firestein GS: Etiology and pathogenesis of rheumatoid arthritis; in Harris ED Jr, Budd RC, Genovese MC, Firestein GS, Sargent JS, Sledge CB (eds): Kelley's Textbook of Rheumatology, ed 7. Philadelphia, Elsevier Saunders, 2005, pp 1013-1042.

18 Steiner G, Tohidast-Akrad M, Witzmann G Vesely M, Studnicka-Benke A, Gal A, Kunaver M, Zenz P, Smolen JS: Cytokine production by synovial $\mathrm{T}$ cells in rheumatoid arthritis. Rheumatology (Oxford) 1999;38: 202-213.

19 Robak T, Gladalska A, Stepien H: The tumour necrosis factor family of receptors/ligands in the serum of patients with rheumatoid arthritis. Eur Cytokine Netw 1998;9: 145-154.

20 Tanabe M, Ochi T, Tomita T,Suzuki R, Sakata T, Shimaoka Y, Nakagawa S, Ono, K: Remarkable elevation of interleukin 6 and interleukin 8 levels in the bone marrow serum of patients with rheumatoid arthritis. J Rheumatol 1994;21:830-835.

21 Sivalingam SP, Yoon KH, Koh DR, Fong KY: Single-nucleotide polymorphisms of the interleukin-18 gene promoter region in rheumatoid arthritis patients: protective effect of AA genotype. Tissue Antigens 2003;62:498504.

22 Toh ML, Miossec P: The role of T cells in rheumatoid arthritis: new subsets and new targets. Curr Opin Rheumatol 2007;19:284288.

23 Kehlen A, Thiele K, Riemann D, Langner J: Expression, modulation and signalling of IL-17 receptor in fibroblast-like synoviocytes of patients with rheumatoid arthritis. Clin Exp Immunol 2002;127:539-546.

24 Ryu S, Lee JH, Kim SI: IL-17 increased the production of vascular endothelial growth factor in rheumatoid arthritis synoviocytes. Clin Rheumatol 2006;25:16-20.

25 Ziolkowska M, Koc A, Luszczykiewicz G, Ksiezopolska-Pietrzak K, Kimczak E, Chwalinska-Sadowska H, Maslinski W: High levels of IL-17 in rheumatoid arthritis patients: IL-15 triggers in vitro IL-17 production via cyclosporin A-sensitive mechanism. J Immunol 2000;164:2832-2838.

26 Mosaad YM, Metwally SS, Auf FA, AbdelSamee ER, el-Deek B, Limon NI, el-Chennawi FA: Proinflammatory cytokines (IL-12 and IL-18) in immune rheumatic diseases: relation with disease activity and autoantibodies production. Egypt J Immunol 2003; 10:19-26.
27 Sato M, Takemura M, Shinohe R, Koishi H, Morita T, Seishima M: Clinical significance of serum IL-18 determination in rheumatoid arthritis (in Japanse). Rinsho Byori 2004;52: 109-114.

28 van Roon JA, Verhoef CM, van Roy JL, Gmelig-Meyling FH, Huber-Bruning $\mathrm{O}$, Lafeber FP, Bijlsma JW: Decrease in peripheral type 1 over type $2 \mathrm{~T}$ cell cytokine production in patients with rheumatoid arthritis correlates with an increase in severity of disease. Ann Rheum Dis 1997;56:656-660.

29 Huang JL, Kuo ML, Hung IJ, Wu CJ, Ou LH, Cheng JH: Lowered IL-4-producing T cells and decreased IL-4 secretion in peripheral blood from subjects with juvenile rheumatoid arthritis. Chang Gung Med J 2001;24: 77-83.

30 Keystone E, Wherry J, Grint P: IL-10 as a therapeutic strategy in the treatment of rheumatoid arthritis. Rheum Dis Clin North Am 1998;24:629-639.

- 31 Chabaud M, Durand JM, Buchs N, Fossiez F, Page G, Frappart L, Miossec P: Human interleukin-17: a T cell-derived proinflammatory cytokine produced by the rheumatoid synovium. Arthritis Rheum 1999;42:963970

- 32 Tokayer A, Carsons SE, Chokshi B, SantiagoSchwarz F: High levels of interleukin 13 in rheumatoid arthritis sera are modulated by tumor necrosis factor antagonist therapy: association with dendritic cell growth activity. J Rheumatol 2002;29:454-461.

-33 Benucci M, Li Gobbi F, Fossi F, Cammelli E, Manfredi M: Peripheral mononuclear cells and cytokine circulating levels during adalimumab therapy in patients with rheumatoid arthritis (in Italian). Recenti Prog Med 2005; 96:424-427.

34 Nissinen R, Leirisalo-Repo M, Peltomaa R, Palosuo T, Vaarala O: Cytokine and chemokine receptor profile of peripheral blood mononuclear cells during treatment with infliximab in patients with active rheumatoid arthritis. Ann Rheum Dis 2004;63:681-687.

35 Schotte H, Schluter B, Willeke P, Mickholz E, Schorat MA, Domschke W, Gaubitz M: Long-term treatment with etanercept significantly reduces the number of proinflammatory cytokine-secreting peripheral blood mononuclear cells in patients with rheumatoid arthritis. Rheumatology (Oxford) 2004; 43:960-964. 